\title{
Pellet to Part Manufacturing System for CNCs
}

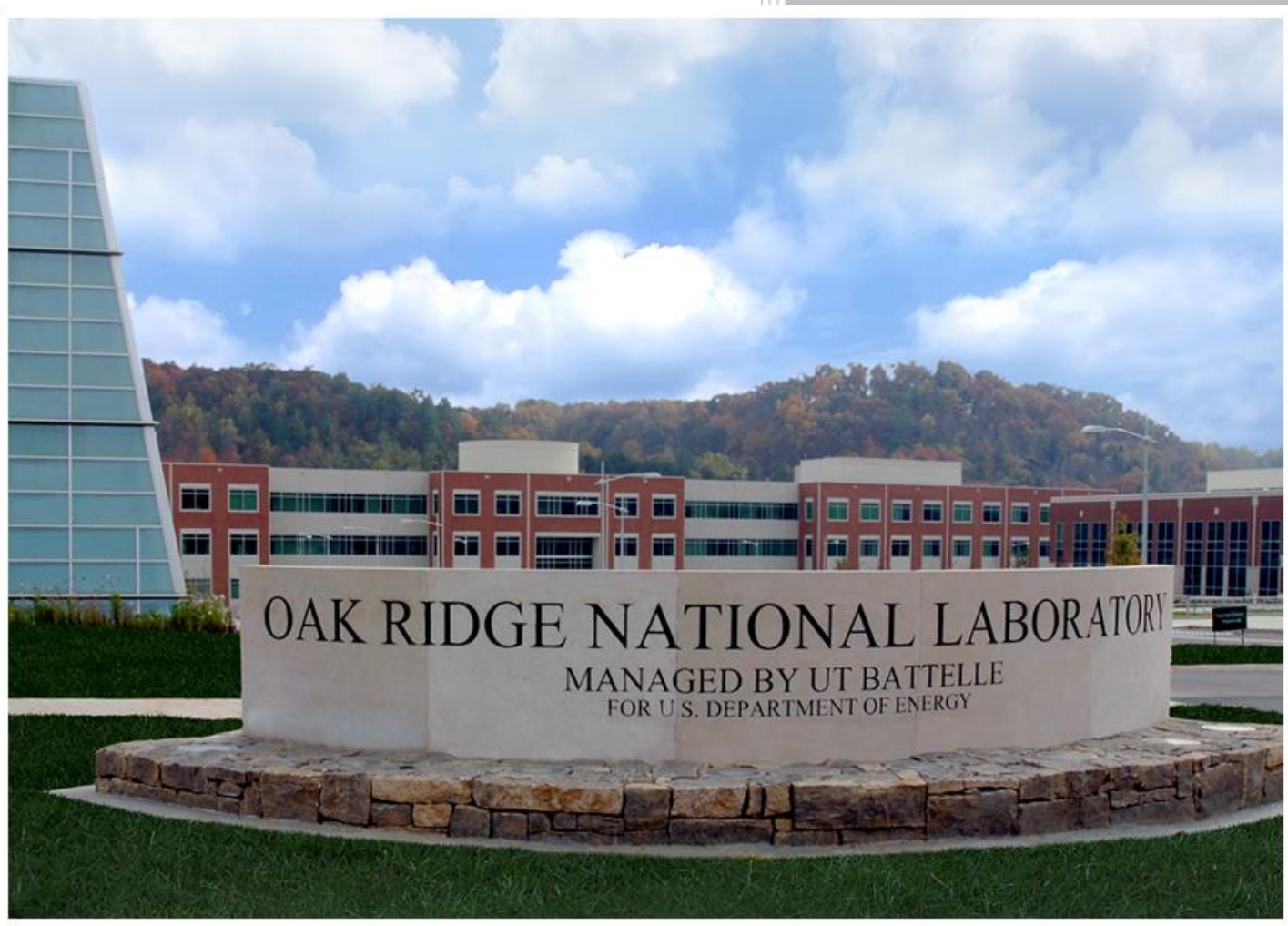

CRADA FINAL REPORT

NFE-16-06052

\section{Approved for Public Release.}

Distribution is Unlimited.
Alex Roschli

Lonnie Love

Brian Post

Phillip Chesser

Peter Lloyd

Yash Bandari

Jason Jones

Katherine Gaul

March 14, 2018 


\section{DOCUMENT AVAILABILITY}

Reports produced after January 1, 1996, are generally available free via US Department of Energy (DOE) SciTech Connect.

Website http://www.osti.gov/scitech/

Reports produced before January 1, 1996, may be purchased by members of the public from the following source:

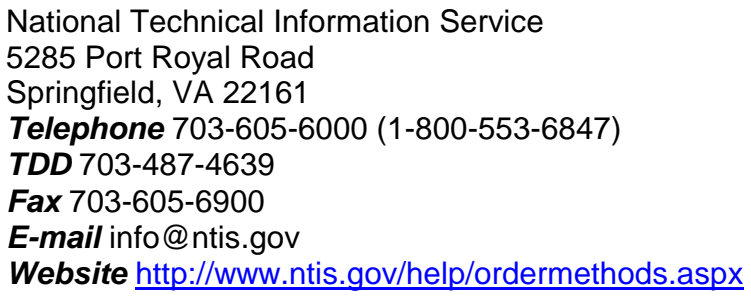

Reports are available to DOE employees, DOE contractors, Energy Technology Data Exchange representatives, and International Nuclear Information System representatives from the following source:

Office of Scientific and Technical Information

PO Box 62

Oak Ridge, TN 37831

Telephone 865-576-8401

Fax 865-576-5728

E-mail reports@osti.gov

Website http://www.osti.gov/contact.html

This report was prepared as an account of work sponsored by an agency of the United States Government. Neither the United States Government nor any agency thereof, nor any of their employees, makes any warranty, express or implied, or assumes any legal liability or responsibility for the accuracy, completeness, or usefulness of any information, apparatus, product, or process disclosed, or represents that its use would not infringe privately owned rights. Reference herein to any specific commercial product, process, or service by trade name, trademark, manufacturer, or otherwise, does not necessarily constitute or imply its endorsement, recommendation, or favoring by the United States Government or any agency thereof. The views and opinions of authors expressed herein do not necessarily state or reflect those of the United States Government or any agency thereof. 
ORNL/TM-2018-807

CRADA/NFE-16-06052

Energy and Transportation Sciences Division Advanced Manufacturing Office

\title{
Pellet to Part Manufacturing System for CNCs
}

\author{
Authors \\ Alex Roschli \\ Lonnie Love \\ Brian Post \\ Phillip Chesser \\ Peter Lloyd \\ Yash Bandari \\ Jason Jones \\ Katherine Gaul
}

Date Published:

March 14, 2018

Prepared by OAK RIDGE NATIONAL LABORATORY

Oak Ridge, Tennessee 37831-6283

managed by

UT-BATTELLE, LLC

for the

US DEPARTMENT OF ENERGY

under contract DE-AC05-00OR22725 
Approved For Public Release 




\section{CONTENTS}

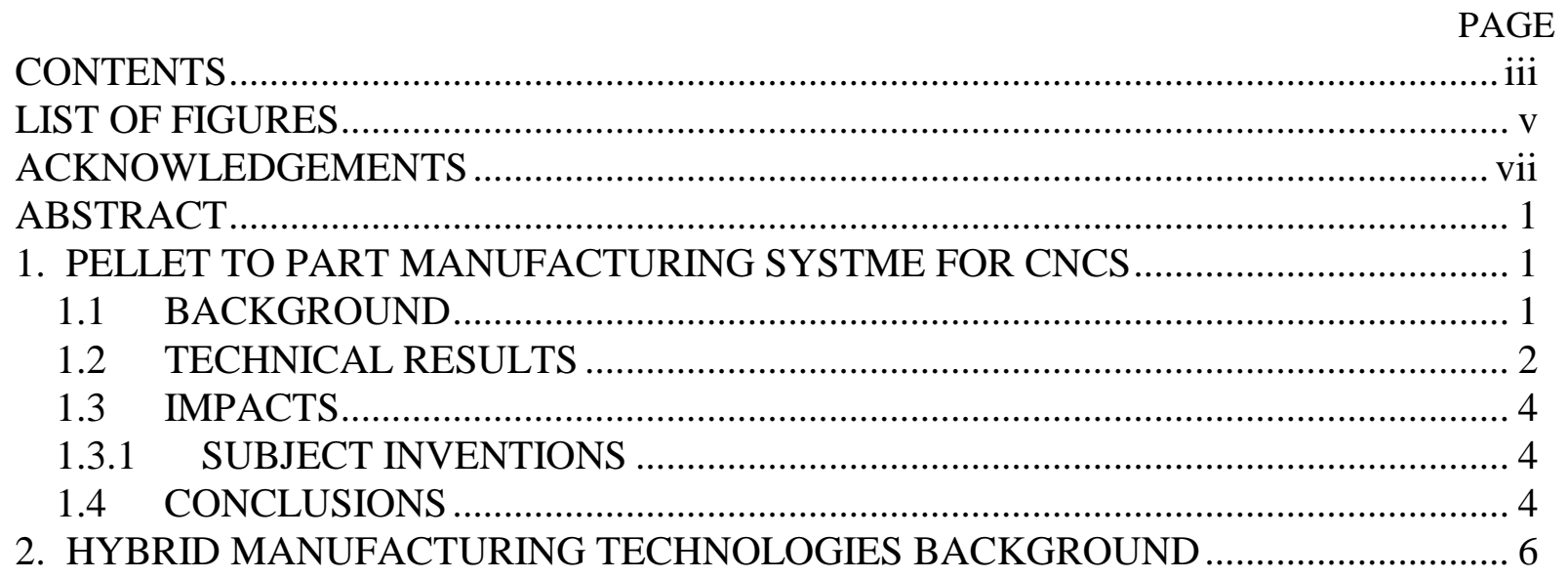




\section{LIST OF FIGURES}

Fig. 1. First generation extruder printing a miniature chair on a Hurco CNC 1

Fig. 2. The second-generation extruder in a testing setup in a Haas VF-5 CNC machine 2

Fig. 3. Early part produced by HMT

Fig. 4. Calibration print showing starts and stops 3

Fig. 5. A hexagon printed with the second-generation extruder using a $3 \mathrm{~mm}$ diameter nozzle on an AMBIT ${ }^{\text {TM}}$-dextrous Haas CNC machine 3

Fig. 6. Parameter development for $5 \mathrm{~mm}$ diameter nozzle with the second-generation extruder on the AMBIT ${ }^{\mathrm{TM}}$-dextrous Haas system 


\section{ACKNOWLEDGEMENTS}

This CRADA NFE-16-06052 was conducted as a Technical Collaboration project within the Oak Ridge National Laboratory (ORNL) Manufacturing Demonstration Facility (MDF) sponsored by the US Department of Energy Advanced Manufacturing Office (CPS Agreement Number 24761).

Opportunities for MDF technical collaborations are listed in the announcement "Manufacturing Demonstration Facility Technology Collaborations for US Manufacturers in Advanced Manufacturing and Materials Technologies" posted at http://web.ornl.gov/sci/manufacturing/docs/FBO-ORNL-MDF2013-2.pdf. The goal of technical collaborations is to engage industry partners to participate in shortterm, collaborative projects within the Manufacturing Demonstration Facility (MDF) to assess applicability and of new energy efficient manufacturing technologies. Research sponsored by the U.S. Department of Energy, Office of Energy Efficiency and Renewable Energy, Advanced Manufacturing Office, under contract DE-AC05-00OR22725 with UT-Battelle, LLC. 


\begin{abstract}
Oak Ridge National Laboratory's Manufacturing Demonstration Facility worked with Hybrid Manufacturing Technologies to develop a compact prototype composite additive manufacturing head that can effectively extrude injection molding pellets. The head interfaces with conventional CNC machine tools enabling rapid conversion of conventional machine tools to additive manufacturing tools. The intent was to enable wider adoption of Big Area Additive Manufacturing (BAAM) technology and combine BAAM technology with conventional machining systems.
\end{abstract}

\title{
1. PELLET TO PART MANUFACTURING SYSTEM FOR CNCS
}

This phase one technical collaboration project (MDF-TC-2016-083) began on February 1, 2016 and was completed on February 14, 2018. The collaboration partner, Hybrid Manufacturing Technologies (HMT), is a small business. A polymer extruder has been successfully developed and integrated with the machine control as well as with ORNL Slicer. Calibration of the machine was completed, which led to successful prints including a miniature chair.

\subsection{BACKGROUND}

HMT is a start-up based outside of Dallas, Texas. HMT's goal is to bridge the gap between additive manufacturing and $\mathrm{CNC}$ subtractive machining. They retrofit existing CNC machines from manufacturers like Hurco (Fig. 1) and Haas (Fig. 2) with their custom designed metal additive heads as well as inspection heads. Using their current technology, HMT can grow a part with their metal heads, through a directed energy deposition (DED) process, and then subtract away any excess material to get the final product to exact shape. This is all done without human intervention by an automated tool change system that can switch between additive and subtractive heads on the CNC. The partnership with ORNL is aimed at increasing the product line at HMT by adding polymer additive manufacturing to their capabilities.

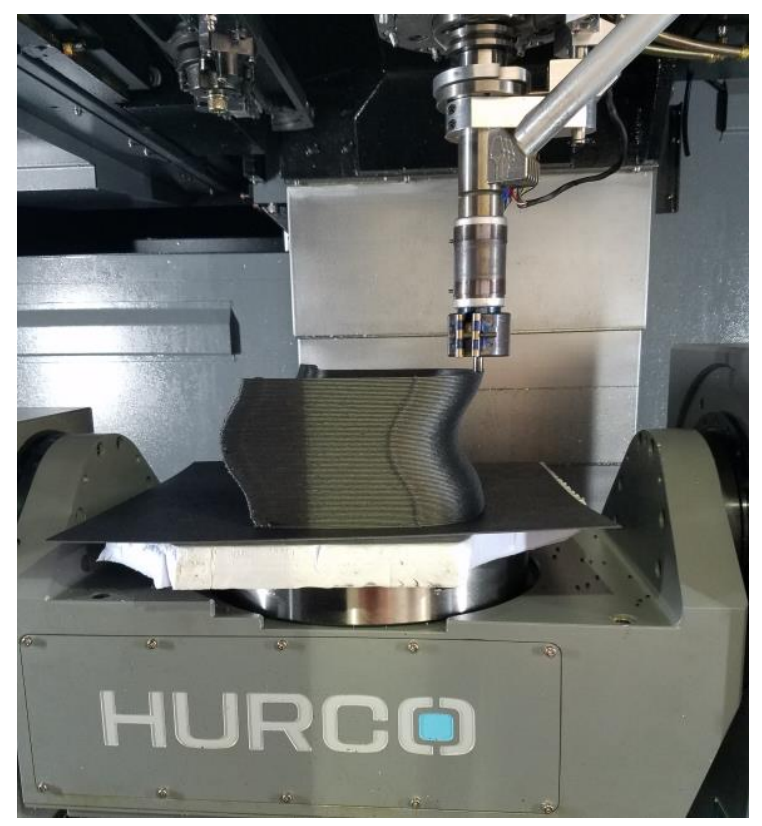

Fig. 1. First generation extruder printing a miniature chair on a Hurco CNC 


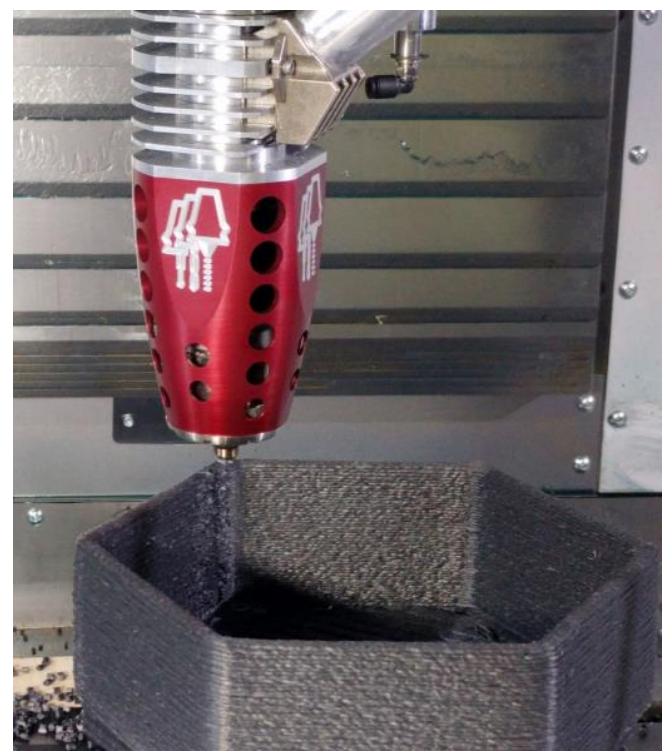

Fig. 2. The second-generation extruder in a testing setup in a Haas VF-5 CNC machine

\subsection{TECHNICAL RESULTS}

HMT designed and engineered a small pellet fed extruder that could be held by a machining spindle leveraging components and the processes from conventional injection molding and extrusion. The extruder needed to be designed specifically for going inside a CNC machine. This meant it had to fit into a tool changer for automatic loading and unloading, but it also needed to mate correctly with a machining spindle, which would be the power source (an approach patented by Hybrid). It also had to be small and light weight. A long barrel reduces the printable z-height of the machine, and a wide barrel doesn't fit the tool changer. The first-generation of this extruder (Fig. 1) was intended to explore if the constraints for tool changeability and practical deposition rates 100x conventional desktop printers could be realized simultaneously. It was bulky and had some design limitations that made it difficult to clean the screw/barrel and difficult to disassemble as needed to measure/track screw wear.

With input from ORNL, a second-generation of the extruder (Fig. 2) was constructed and saw many improvements over the first generation. The weight was reduced by $30 \%$ (down to less than $4 \mathrm{~kg}$ ), which meant less mass to heat up and resulted in faster heating and cooling times for the extruder. A mounting redesign meant nozzles could be easily removed without any further disassembly. The screw can now be removed through the top or bottom of the extruder as needed for cleaning and replacement.

At the start of the partnership with ORNL, HMT was struggling to make usable parts from the polymer extruder (Fig. 3). With assistance from ORNL, HMT was able to quantify the extruder by recording flowrates and doing calibration prints (Fig. 4). Figure 4 shows a calibration print used to properly determine flowrates for varying corner radii and start and stop parameters. The corner of the print shown in the center of the photo shows the start and stop location of the print known as the seam. With proper tuning, the start and stop becomes less noticeable. This tuning is done through ORNL Slicer. A specific syntax was created for each of the two HMT hybridized machines, Haas and Hurco. The software and parameters were modified specifically for the process as desired by HMT to allow 
them to print end-use parts (Figs. 5 and 6). Chopped carbon fiber reinforced acrylonitrile butadiene styrene (ABS) plastic pellets has proven to be a successful and reliable feedstock for the HMT system.

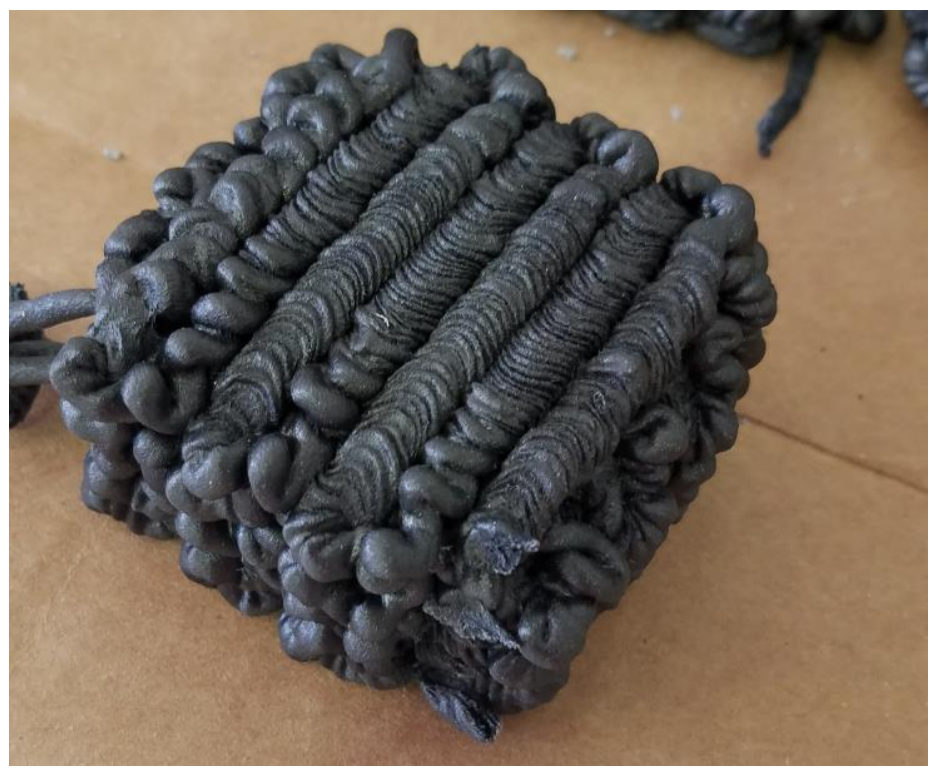

Fig. 3. Early part produced by HMT

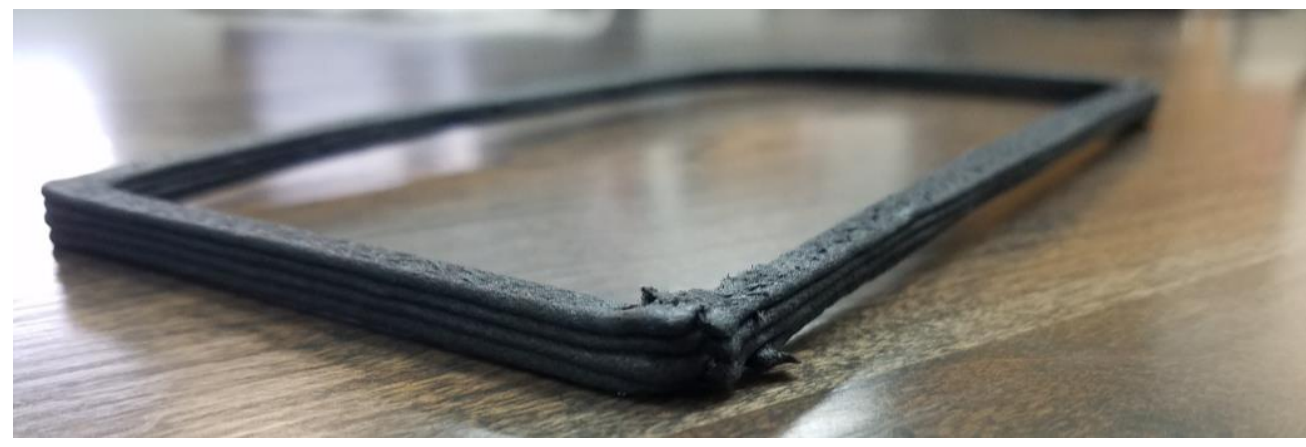

Fig. 4. Calibration print showing starts and stops

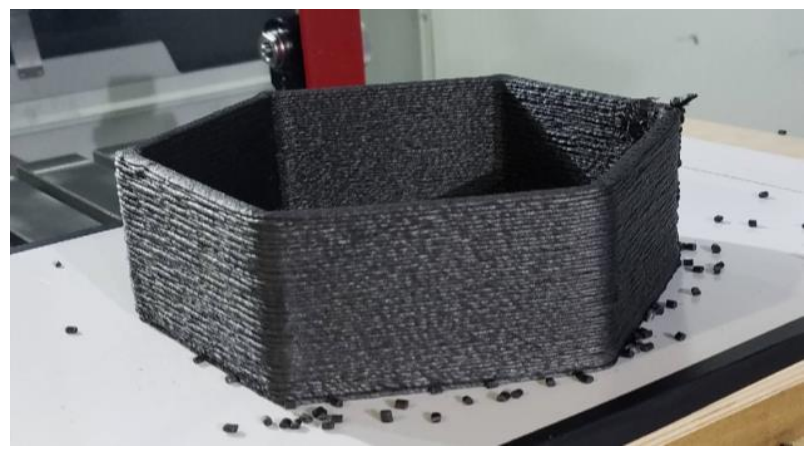

Fig. 5. A hexagon printed with the second-generation extruder using a 3mm diameter nozzle on an

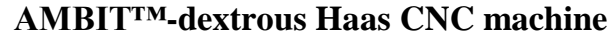



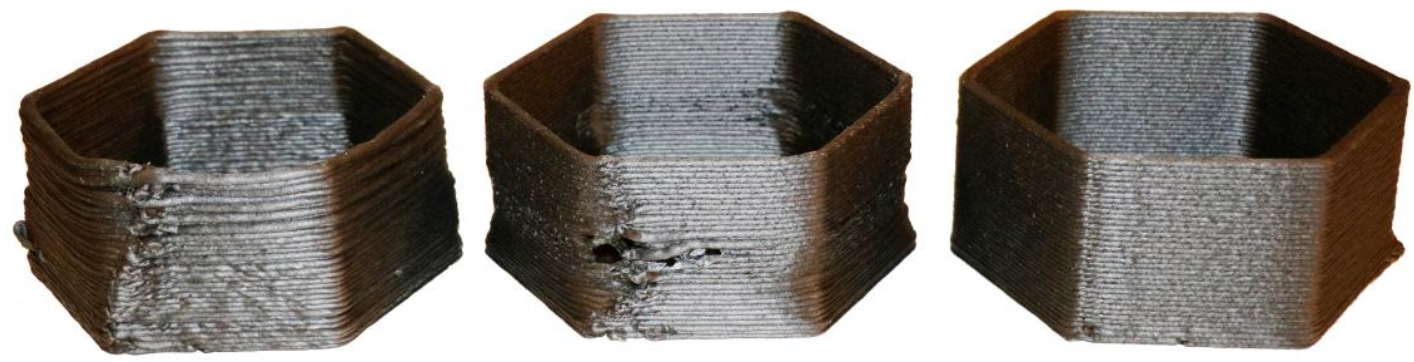

Fig. 6. Parameter development for $5 \mathrm{~mm}$ diameter nozzle with the second-generation extruder on the AMBIT $^{\text {TM-dextrous Haas system }}$

\subsection{IMPACTS}

The impacts of this project are significant. This project lays the groundwork to give virtually any floor standing CNC machine tool owner the ability to upgrade their CNC machine to extrude polymer for additive manufacturing capabilities. The ability to convert an existing $\mathrm{CNC}$ machine to have extrusion capabilities creates and easy adoption path for BAAM technology, which costs significantly less than investing in conventional industrial grade filament extruders. Facilitating the automated switch from extrusion to machining enables the ability to machine extruded parts in-process, which realizes the freedoms of additive manufacturing without sacrificing machining tolerances and surface finishes.

Moving forward, HMT plans to continue developing this system, which will provide the ability to add metal and polymer materials in this additive and subtractive manufacturing process. This will enable multi-material parts to be produced using both materials as either build or support material. Adding polymer directly onto metal components can provide a cheap, efficient sacrificial material for work holding, which has the potential to reduce the complexity of metal part repair (a workflow claimed in an HMT patent).

\subsubsection{SUBJECT INVENTIONS}

There are no subject inventions that resulted from this project.

\subsection{CONCLUSIONS}

Polymer additive manufacturing has been successfully adapted to work within the HMT system, giving them a new product line. The second-generation extruder has proven to be very responsive and reliable with carbon fiber ABS pellets. ORNL Slicer has been fully integrated for use with both Haas and Hurco CNC machines with the polymer additive manufacturing. The next step for HMT is to distribute the new polymer head to clients to begin field testing, which is scheduled for the end of March 2018. The next step for ORNL is to continue working on material development and calibration strategies so that the HMT process can be extended to new industries. 


\section{HYBRID MANUFACTURING TECHNOLOGIES BACKGROUND}

In 2007, the founders of HMT undertook the task of developing a solution to marry the freedoms of additive manufacturing with the precision of CNC machining. The key objectives were to provide a practical means for hybrid manufacturing. This included the development of robust and compact directed energy deposition heads and integration methods that did not require modification of the structural parts of the CNC machine.

In 2007, active use of a high-speed milling machine was initiated at De Montfort University's Additive Manufacturing (AM) and 3D printing research laboratory. The cross-pollination of additive and subtractive technologies led to a 4-year UK-based research project named RECLAIM (REmanufacture of high value products using a Combined LAser cladding, Inspection and Machining system) with support from the Technology Strategy Board. This research endeavor has matured into the AMBIT ${ }^{\mathrm{TM}}$ tool-changeable deposition system. Project collaborators included: Airfoil Technologies International Llc, Cummins Inc, De Montfort University, Delcam plc, Electrox Ltd, Manufacturing Technology Centre Ltd, TWI Ltd, Precision Engineering Technologies Ltd, and Renishaw plc.

Commercial exploitation led to the formal founding of HMT in 2012 by Dr. Jason Jones and Peter Coates as a spin-off from a collaborative research and development project. 